\title{
Viabilidade econômica da farinha de cará na alimentação de poedeiras comerciais leves
}

\author{
Economical availability of cará flour in diets for commercial laying hens
}

\author{
MELO, Ramon Duque ${ }^{1}$; CRUZ, Frank George Guimarães ${ }^{2 *}$; FEIJÓ, Julmar da Costa ${ }^{1}$; \\ RUFINO, João Paulo Ferreira ${ }^{3}$; MELO, Lucas Duque ${ }^{1}$; COSTA, Ana Paula Guimarães \\ Cruz $^{1}$
}

\author{
${ }^{1}$ Universidade Federal do Amazonas, Faculdade de Ciências Agrárias, Curso de Zootecnia, Manaus, \\ Amazonas, Brasil. \\ ${ }^{2}$ Universidade Federal do Amazonas, Faculdade de Ciências Agrárias, Departamento de Produção Animal \\ e Vegetal, Manaus, Amazonas, Brasil. \\ ${ }^{3}$ Universidade Federal do Amazonas, Faculdade de Ciências Agrárias, Programa Pós-Graduação em \\ Ciência Animal, Manaus, Amazonas, Brasil. \\ *Endereço para correspondência: frankgcruz@gmail.com
}

\section{RESUMO}

O objetivo com este estudo foi verificar a viabilidade econômica da inclusão de níveis crescentes de farinha de cará em rações para poedeiras comerciais leves. O experimento teve duração de 84 dias divididos em quatro períodos de 21 dias cada. Foram utilizadas 144 poedeiras da linhagem Hissex White com 39 semanas de idade. A farinha de cará foi inclusa nas rações como fonte energética. $\mathrm{O}$ delineamento experimental foi o inteiramente casualizado constituído de seis tratamentos correspondentes a níveis de inclusão de farinha de cará $(0,5,10,15,20$ e $25 \%)$ com quatro repetições de seis aves cada. Os dados coletados foram analisados utilizando regressão polinomial. Foram observadas diferenças significativas $(\mathrm{P}>0,05)$ na análise econômica de custo alimentar relacionada com a produção de ovos e na análise de receita e lucratividade das poedeiras, obtendo-se melhores resultados no nível de $5 \%$ de inclusão de farinha de cará nas rações, e decréscimo na rentabilidade a medida que se aumenta os níveis de inclusão. A partir dos resultados encontrados, concluiu-se, portanto, que a farinha de cará pode ser utilizada como alimento alternativo em rações de poedeiras comerciais leves, tendo o nível de 5\% de inclusão apresentado melhores resultados de desempenho econômico. A partir de $15 \%$ de inclusão, observam-se perdas econômicas significativas.

Palavras-chave: alimento alternativo, custo, rentabilidade, valor agregado bruto

\section{SUMMARY}

The objective of this study was to analyze the economical availability of cará flour in diets for laying hens. The experiment lasted 84 days in four periods of 21 days. 144 Hissex White hens with 39 weeks of age were used. Cará flour was used as diets energy source. The experimental design was completely randomized with six treatments of cará flour levels $(0,5,10,15,20$ and $25 \%$ ) with four replicates of six birds each. The data were analyzed for polynomial regression at $5 \%$ of significance. Significant differences were observed $(\mathrm{P}>0.05)$ in the economic analysis of food costs in egg production, revenue analysis and profitability of laying hens, with better results at $5 \%$ of cará flour inclusion. Observed too a decrease in profitability from these inclusion levels. From these results, it was concluded that the cará flour can be used as an energy alternative food in diets for commercial laying hens, with the inclusion level of 5\% shown better results of economic performance. From 15\% of inclusion, observed significant economic losses.

Keywords: alternative food, cost, gross value added, profitability 


\section{INTRODUÇÃO}

A crescente demanda por alimentos balanceados utilizados em rações para aves, somados ao alto custo e à crescente utilização de alguns desses alimentos para o consumo humano, tem sido fatores que tem motivado os pesquisadores atualmente a buscarem alimentos alternativos, principalmente substitutos do milho (fonte de energia) e farelo de soja (fonte de proteína) (CRUZ, 2011), a fim de equacionar problemáticas de escassez de grãos que atendam a produção animal nacional, sendo a avicultura um dos segmentos que mais exigem grãos ou substitutos a esses em suas dietas balanceadas (LOUREIRO et al., 2007; TOGASHI et al., 2008).

Em algumas regiões do Brasil, a restrição de recursos, e o alto valor das matérias primas tem demandado pesquisas com alimentos alternativos em rações para aves visando, principalmente, minimizar estes custos com alimentação, tendo em vista que estes correspondem à cerca de $70 \%$ dos custos totais de produção (CRUZ, 2016).

Neste contexto, uma das alternativas com potencial para inclusão em rações para poedeiras é a farinha de cará (Dioscorea trifida L.), devido a crescente produção do mesmo na região Amazônica. O cará é uma espécie de inhame comestível originária da América do Sul, que em conjunto com outras espécies importantes economicamente do gênero Dioscorea, é mantida por pequenos agricultores tradicionais. Suas túberas apresentam na sua composição carboidratos, proteínas, sais minerais e vitaminas, bem como propriedades antimicrobianas, diuréticas e energéticas (RAMOS-ESCUDERO et al., 2010; FEIJÓ et al., 2016).
Outrora, pesquisas com ingredientes alternativos para aves verificaram, além do aspecto nutricional e zootécnico, a importância da análise econômica dos resultados experimentais, uma vez que produtores e especialistas, a partir destes resultados em conjunto, disporão de melhores critérios que irão contribuir para utilização dos mesmos de forma mais cautelosa e eficiente (SILVA et al., 2009; SANTOS \& GRANJEIRO, 2012; RUFINO et al. 2015).

Portanto, com base nestas informações e a crescente busca por resultados quanto à viabilidade e aplicação econômica de alimentos alternativos, realizou-se este estudo com o objetivo de verificar a viabilidade econômica da farinha de cará em rações para poedeiras comerciais leves.

\section{MATERIAL E MÉTODOS}

O experimento foi conduzido no Setor de Avicultura do Departamento de Produção Animal e Vegetal da Faculdade de Ciências Agrárias da Universidade Federal do Amazonas, localizado no Setor Sul do Campus Universitário, Manaus/AM, divididos em quatro ciclos de 21 dias cada. Foram utilizadas 144 aves da linhagem Hissex White com 39 semanas de idade alojadas em gaiolas de arame galvanizado medindo $1,00 \mathrm{x} 0,40 \mathrm{x}$ $0,45 \mathrm{~cm}$.

As aves foram distribuídas em um delineamento inteiramente casualizado com seis níveis de inclusão de farinha de cará $(0,5,10,15,20$ e $25 \%)$ nos tratamentos e quatro repetições de seis aves cada. Foi adotado um período de adaptação às rações experimentais e as instalações de sete dias antes do inicio do experimento. 
Todo o cará utilizado no experimento (Dioscorea trifida L. var. roxo) foi adquirido na forma in natura de uma só vez junto a feiras e mercados existentes na cidade de Manaus. Após a coleta, foi selecionado o material de melhor aspecto, rejeitando-se o material em decomposição. A seguir, o material foi lavado para retirada de terra e resíduos, submetido à secagem ao ar durante quatro dias e, posteriormente, triturado em equipamento de trituração de grãos (peneira de 6mm). A composição centesimal da farinha de cará encontrase na Tabela 1 .

Tabela 1. Composição centesimal da farinha de cará ${ }^{1}$

\begin{tabular}{|c|c|}
\hline Componentes & Composição \\
\hline Matéria Seca, \% & 95,54 \\
\hline Proteína Bruta, \% & 2,65 \\
\hline Fibra Bruta, \% & 2,69 \\
\hline Fibra Detergente Neutro, \% & 7,45 \\
\hline Fibra Detergente Ácido, \% & 3,64 \\
\hline Gordura, $\%$ & 0,31 \\
\hline Matéria Mineral, \% & 3,23 \\
\hline Extrato Não Nitrogenado, \% & 86,66 \\
\hline Energia Bruta, Kcal $/ \mathrm{kg}$ & 3730,73 \\
\hline $\begin{array}{l}\text { Energia Metabolizável, } \\
\mathrm{Kcal} / \mathrm{kg}\end{array}$ & $3489,81^{2}$ \\
\hline \multicolumn{2}{|c|}{$\begin{array}{l}\text { Composição descrita por Melo et al. (2015). } \\
{ }^{1} \text { Foi determinada através do método de } \\
\text { cálculo para energia metabolizável aparente } \\
\text { conforme descrito por Rostagno et al. (2011), } \\
\text { onde obteve-se o valor em } \mathrm{kcal} \mathrm{kg}^{-1} \text {. }\end{array}$} \\
\hline
\end{tabular}

As rações isonutritivas foram formuladas utilizando o software computacional Supercrac (2004) em atendimento as exigências nutricionais das aves e conforme os valores dos ingredientes fornecidos pelas Tabelas Brasileiras para Aves e Suínos (ROSTAGNO et al., 2011), com exceção da composição da farinha de cará, e encontram-se na Tabela 2.
A água e as rações foram fornecidas at libitum às aves em bebedouros do tipo nipple e comedouros do tipo calha. Durante todo o período experimental foram fornecidas 16 horas de luz/dia (natural + artificial). Todas as aves foram pesadas no início do experimento para uniformização das parcelas a apresentaram peso médio de 1,54 \pm $0,16 \mathrm{~kg}$. A coleta de ovos foi realizada três vezes ao dia (às 8,11 e 16hs) sendo registrada cada ocorrência. Ao final de cada ciclo as folhas de controle de produção foram recolhidas para determinação da produção de ovos, a partir do total produzido comercializável por cada parcela, e a sobra de ração dos comedouros foi pesada para determinação do consumo acumulado de ração de cada período.

As variáveis analisadas foram: consumo de ração acumulado (kg), custo alimentar (R\$), produção de ovos, custo de produção dos ovos ( $\mathrm{R} \$)$, receita bruta $(\mathrm{R} \$)$, valor agregado bruto $(\mathrm{R} \$)$, índice de lucratividade (\%) e ponto de equilíbrio.

Para determinação do preço da ração e dos custos de produção foram utilizados apenas os valores por quilo das matérias-primas utilizadas e o preço atualizado destas na região no período de realização do experimento, que foram: milho, R\$ 0,30; farelo de soja, $\mathrm{R} \$ 1,20$; calcário, $\mathrm{R} \$ 0,41$; fosfato bicálcico, sal comum, R\$ 0,40; R\$ 1,92; DL-Metionina, R\$ 12,50; L-Lisina, R\$ 10,80 ; e suplemento mineral e vitamínico, R\$ 9,98. Para o cálculo do custo da farinha de cará levou-se em consideração apenas as despesas com transporte e manejo do produto, e estimou-se o preço por quilo do produto em R\$ 0,30. Os custos fixos não se alteraram à curto prazo durante $o$ período experimental, sendo considerados constantes para todos os tratamentos. 
Rev. Bras. Saúde Prod. Anim., Salvador, v.18, n.2, p.221-230 abr./jun., 2017

Tabela 2. Composição das rações contendo farinha de cará

\begin{tabular}{|c|c|c|c|c|c|c|}
\hline \multirow{2}{*}{ Ingredientes } & \multicolumn{6}{|c|}{ Níveis de farinha de cará (\%) } \\
\hline & 0 & 5 & 10 & 15 & 20 & 25 \\
\hline Milho $(7,88 \%)$ & 61,665 & 56,425 & 51,185 & 45,94 & 40,705 & 35,465 \\
\hline F. soja $(46 \%)$ & 25,766 & 25,982 & 26,2 & 26,415 & 26,635 & 26,853 \\
\hline Farinha de cará & 0,000 & 5,000 & 10,000 & 15,000 & 20,000 & 25,000 \\
\hline Calcário calcítico & 9,769 & 9,763 & 9,754 & 9,757 & 9,740 & 9,735 \\
\hline Fosfato bicálcico & 1,695 & 1,710 & 1,725 & 1,739 & 1,756 & 1,769 \\
\hline Premix vit. min. ${ }^{1}$ & 0,500 & 0,500 & 0,500 & 0,500 & 0,500 & 0,500 \\
\hline DL- Metionina (99\%) & 0,255 & 0,270 & 0,286 & 0,299 & 0,314 & 0,328 \\
\hline Sal & 0,350 & 0,350 & 0,350 & 0,350 & 0,350 & 0,350 \\
\hline Total & 100,00 & 100,00 & 100,00 & 100,00 & 100,00 & 100,00 \\
\hline Nutriente & \multicolumn{6}{|c|}{ Níveis nutricionais } \\
\hline E.M, $\mathrm{kcal}^{-1} / \mathrm{kg}$ & 2.678 & 2.686 & 2.694 & 2.702 & 2.710 & 2.718 \\
\hline Proteína bruta, \% & 17,000 & 17,000 & 17,000 & 17,000 & 17,000 & 17,000 \\
\hline Metionina + Cistina, \% & 0,786 & 0,786 & 0,786 & 0,786 & 0,786 & 0,786 \\
\hline Metionina, \% & 0,520 & 0,527 & 0,535 & 0,550 & 0,550 & 0,558 \\
\hline Cálcio, \% & 4,200 & 4,200 & 4,200 & 4,200 & 4,200 & 4,200 \\
\hline Fósforo Disponível, \% & 0,400 & 0,400 & 0,400 & 0,400 & 0,400 & 0,400 \\
\hline Sódio, \% & 0,156 & 0,155 & 0,154 & 0,152 & 0,152 & 0,151 \\
\hline
\end{tabular}

${ }^{\mathrm{I}}$ Níveis de garantia por quilograma de produto: Vitamina A 2.000.000 UI, Vitamina D3 400.000 UI, Vitamina E $2.400 \mathrm{mg}$, Vitamina K3 $400 \mathrm{mg}$, Vitamina B1 $100 \mathrm{mg}$, Vitamina B2 $760 \mathrm{mg}$, Vitamina B6 $100 \mathrm{mg}$, Vitamina B12 $2.400 \mathrm{mcg}$, Niacina $5.000 \mathrm{mg}$, Pantotenato de Cálcio $2000 \mathrm{mg}$, Ácido Fólico 50 $\mathrm{mg}$, Cocciostático $12.000 \mathrm{mg}$, Colina $50.000 \mathrm{mg}$, Cobre $1.200 \mathrm{mg}$, Ferro $6.000 \mathrm{mg}$, Manganês 14.000 $\mathrm{mg}$, Zinco $10.000 \mathrm{mg}$, Iodo $100 \mathrm{mg}$. Selênio $40 \mathrm{mg}$. Veículo Q.S.P. $1.000 \mathrm{~g}$.

O custo alimentar (CA), único custo de produção utilizado como variável foi determinado através da aquisição dos ingredientes e confecção da ração, sendo estimado pela formula: $\mathrm{CA}=$ CRA $\mathrm{x}$ PR, onde $\mathrm{CA}=$ custo com alimentação $(\mathrm{R} \$), \mathrm{CRA}=$ consumo de ração acumulado $(\mathrm{kg})$ e $\mathrm{PR}=$ preço do quilo de ração $(\mathrm{R} \$ / \mathrm{kg})$. O custo de produção por ovos foi obtido do quociente do total de ovos produzidos pelo custo total de produção dos ovos, neste caso o custo alimentar, pela fórmula, $\mathrm{CPO}=\mathrm{Q} / \mathrm{CA}$, onde $\mathrm{CP}=$ custo de produção por ovo, $\mathrm{Q}=$ quantidade de ovos produzidos, e $\mathrm{CA}=$ custo alimentar.

A receita bruta foi obtida a partir do calculo de acordo com a produção de ovos e o preço de venda por unidade do produto, em que $\mathrm{RB}=\mathrm{Q} \times \mathrm{PV}$, onde $\mathrm{RB}$ $=$ receita bruta $(\mathrm{R} \$), \mathrm{Q}-$ quantidade de ovos produzidos por unidade, e $\mathrm{PV}=$ preço de venda de cada ovo. O preço de venda dos ovos, aplicando cálculo de margem bruta de valor agregado bruto, determinou-se através do preço praticado na região com o valor fixo de $\mathrm{R} \$ 0,24$.

$\mathrm{O}$ valor agregado bruto (VAB) denota do cálculo monetário entre a diferença do total acumulado da venda dos ovos com o custo descontado de produção que oriunda do custo com alimentação. A dedução entre a receita bruta e o custo com alimentação foi determinado pela formula, $\mathrm{VAB}=\mathrm{RB}-\mathrm{CA}$ em que $\mathrm{VAB}=$ valor agregado bruto $(\mathrm{R} \$), \mathrm{CA}$ $=$ custo com alimentação $(\mathrm{R} \$)$ e $\mathrm{RB}=$ receita bruta $(\mathrm{R} \$)$. Logo, o índice de lucratividade indica a taxa disponível de capital após o pagamento dos custos, no caso, o custo com alimentação e é oriundo da relação entre a margem de valor agregado bruto e a receita bruta, através da fórmula: $\mathrm{IL}=(\mathrm{VAB} / \mathrm{RB}) \mathrm{x}$ 100. 
$\mathrm{O}$ ponto de equilíbrio define a quantidade de produção que apresente retorno zero. No caso, trata-se de ponto de equilíbrio parcial, pois apresenta o volume de produção necessário para cobrir apenas os custos com alimentação. Sendo assim, considerando que a RB é produto entre a Quantidade de ovo produzido por unidade (Q) e o preço de venda cada ovo (PV), e o Custo de Produção $(\mathrm{CP})$ é produto entre a quantidade de ração consumida e o preço da ração conforme tratamento utilizado temos: $\mathrm{RB}=\mathrm{Q} \times \mathrm{PV}$ e, $\mathrm{CP}=$ CRA x PR. Logo, o ponto de equilíbrio se estabelece quando: $\mathrm{RB}=\mathrm{CP}$, receita bruta é igual ao custo de produção, ou, $\mathrm{Q} \times \mathrm{PV}=\mathrm{CRA} \times \mathrm{PR}$.

A análise variância foi realizada pelo programa computacional SAS (2008) e as estimativas dos tratamentos foram submetidas à análise de regressão polinomial à $5 \%$ de significância. Os modelos para determinação do comportamento das variáveis teve como base a significância de cada parâmetro da equação, o valor do coeficiente de determinação e a consonância do nível estimado.

\section{RESULTADOS E DISCUSSÃO}

Os resultados referentes à análise econômica do custo alimentar e da produção de ovos encontram-se na Tabela 3. Foram observadas diferenças significativas $(\mathrm{P}<0,05)$ no consumo de ração acumulado $\left(\mathrm{Y}=0,2498 \mathrm{x}^{2}\right.$ $2,931 \mathrm{x}+58,42)$ e custo alimentar $(\mathrm{Y}=$ $\left.0,3793 x^{2}-3,561 x+80,23\right)$, onde através da derivação das equações de regressão foi possível obter o ponto de máximo consumo acumulado de ração $(49,82 \mathrm{~kg})$ e melhor custo alimentar $(71,87 \mathrm{~kg})$ ao nível de $5,00 \%$ de inclusão de farinha de cará nas rações.

Tabela 3. Análise econômica de custo alimentar e produção de ovos de poedeiras alimentadas com rações contendo farinha de cará.

\begin{tabular}{|c|c|c|c|c|c|c|c|c|}
\hline \multirow{2}{*}{ Variáveis } & \multicolumn{6}{|c|}{ Níveis de inclusão de farinha de cará (\%) } & \multirow{2}{*}{$\mathrm{R}^{2}$} & \multirow{2}{*}{$\begin{array}{l}\text { CV } \\
(\%)\end{array}$} \\
\hline & 0 & 5 & 10 & 15 & 20 & 25 & & \\
\hline Preço da ração $(\mathrm{R} \$)$ & 1,45 & 1,54 & 1,63 & 1,73 & 1,82 & 1,92 & - & - \\
\hline Consumo de ração $(\mathrm{kg})^{*}$ & 54,52 & 55,84 & 52,36 & 47,71 & 51,48 & 52,36 & 0,41 & 4,08 \\
\hline Custo alimentar $(\mathrm{R} \$)^{*}$ & 79,06 & 86,00 & 85,67 & 82,63 & 94,15 & 95,86 & 0,58 & 4,39 \\
\hline Produção de ovos* & 380,01 & 358,85 & 260,06 & 267,12 & 207,64 & 177,40 & 0,64 & 21,11 \\
\hline Custo de produção $(\mathrm{R} \$)^{*}$ & 0,21 & 0,24 & 0,34 & 0,31 & 0,56 & 0,61 & 0,46 & 4,55 \\
\hline
\end{tabular}

$\mathrm{CV}=$ coeficiente de variação, *Efeito quadrático $(\mathrm{P}<0,05), \mathrm{R}^{2}$ - Coeficiente de determinação.

Outrora, ao fixar o preço da ração em 1,54 (a partir do preço obtido do máximo consumo), foi possível estimar o ponto ótimo econômico para o consumo de ração no nível de $4,67 \%$ de inclusão de farinha de cará por quilo de ração, o que representou uma redução de até $\mathrm{R} \$ 10,85$ no custo de produção da ração em relação ao ponto máximo de produção. Economicamente, a partir da inclusão dos níveis de farinha de cará até $25 \%$ na ração, verificou-se aumento de até $\mathrm{R} \$ 0,50$ no preço da ração por quilo, representando um acréscimo bruto de até $\mathrm{R} \$ 21,4772$ no custo alimentar total levando em consideração a diferença entre o consumo da ração referência e da ração com $25 \%$ de inclusão de farinha de cará. 
Neste sentido, Bastos et al. (2007), Pelizer et al. (2007) e Costa et al. (2009) afirmaram que fatores como facilidade de aquisição, produção e flutuação dos preços dos insumos devem ser considerados na decisão pela utilização ou não de um ingrediente alternativo, e estes são parâmetros que auxiliam na comprovação se há ou não viabilidade econômica que recomende a utilização de determinado produto alternativo nas rações.

Outrora, também foram observadas diferenças significativas $(\mathrm{P}<0,05)$ para produção de ovos $\left(\mathrm{Y}=1,998 \mathrm{x}^{2}\right.$ $55,688 \mathrm{x}+439,79)$, onde a partir da derivação da função obteve-se a maior produção de ovos (430,52 unidades) no nível de inclusão de $14,68 \%$ de farinha de cará nas rações. Por conseguinte, Freitas et al. (2005) descrevem que dentre os fatores que podem afetar diretamente a produção de ovos de aves submetidas a alimentos alternativos, destacam-se a digestibilidade e valor biológico do alimento em questão, sendo estes componentes essenciais para a análise da relação custo beneficio a nível produtivo deste, em conjunto com a resposta fisiológica do animal e os caracteres econômicos.

Cruz et al. (2006) e Lima et al. (2007) trabalhando com apara de mandioca e farelo de coco em rações para poedeiras, respectivamente, também como fonte energética a partir da inclusão de alimentos com alto teor de carboidratos livres, verificaram desempenho semelhante aos obtidos com a utilização de farinha de cará nas rações, entretanto, obtendo melhores resultados quanto aos custos alimentares quando estes foram relacionados com o desempenho das poedeiras como resposta fisiológica.

Nesta abordagem, evidencia-se que nem sempre alimentos alternativos com resposta de desempenho semelhante, possuem a mesma predileção para utilização quando avaliado o seu potencial de utilização relacionado com os aspectos econômicos, principalmente, pois nesse processo de escolha leva-se em consideração uma série de fatores, como o preço do alimento alternativo no mercado, sua disponibilidade ao longo do ano, logística de produção e transporte, dentre outros que podem influenciar diretamente na decisão de se utilizar ou preterir a sua inclusão em rações avícolas. Quanto ao custo de produção dos ovos, também foram observadas diferenças significativas $(\mathrm{P}<0,05)$ onde a partir da derivação da função quadrática $(\mathrm{Y}=$ $\left.0,0124 x^{2}-0,0025 x+0,2003\right)$, obteve-se o melhor custo de produção dos ovos ( $\mathrm{R} \$ 0,1876$ à unidade) no nível $1,08 \%$ de inclusão de farinha de cará nas rações.

Instantaneamente, verifica-se um aumento substancial de $\mathrm{R} \$ 0,40$ no custo de produção da unidade do ovo, ou custo final do produto. Este aumento torna-se o reflexo decorrente do custo atribuído a farinha de cará, e como esta vai gradativamente encarecendo o quilo da ração à medida que aumentam-se os níveis de inclusão desta, discordando de Franzoi et al. (1998) e Togashi et al. (2008) que afirmam que certamente um dos pilares primordiais ao se realizar estudos fontes alternativas e alimentos não convencionais é que estes visam reduzir o custo das rações mantendo o bom desempenho dos animais, e não encarecer ainda mais tanto a ração como o produto final, fato este que foi observado na inclusão de farinha de cará em rações para poedeiras.

Os resultados referentes à análise de receita e lucratividade estão dispostos na Tabela 4. Foram observadas diferenças significativas $(\mathrm{P}<0,05)$ na receita bruta $\left(Y=7,992 \mathrm{x}^{2}-22,27 \mathrm{x}+\right.$ $175,91)$ e no valor agregado bruto $(\mathrm{Y}=$ $\left.4,198 x^{2}-22,63 x+95,68\right)$, onde através da derivação das equações de regressão 
foi possível obter o ponto de máxima receita bruta $(\mathrm{R} \$ 160,39)$ e melhor valor agregado bruto ( $\mathrm{R} \$ 65,18)$ ao nível de $2,69 \%$ de inclusão de farinha de cará nas rações.

Verificou-se uma relação direta entre a inclusão crescente de farinha de cará nas rações e redução gradativa na receita bruta e no valor agregado bruto, onde a partir do nível de 20\% apresentou condição de prejuízo econômico. Estes resultados corroboram com a análise de custo realizada anteriormente, e minimizam ainda mais o potencial de utilização da farinha de cará em rações para poedeiras, principalmente pelo custo oneroso que esta demonstrou demandar como matéria prima e, pelo seu potencial biológico de atuação como fonte energética, proporcionar resultados bem abaixo do milho (principal fonte energética das rações) nas rações.

Tabela 4. Análise de receita e lucratividade do desemprenho de poedeiras alimentadas com rações contendo farinha de cará

\begin{tabular}{lcccccccc}
\hline \multirow{2}{*}{ Variáveis } & \multicolumn{9}{c}{ Níveis de inclusão de farinha de cará (\%) } & \multirow{2}{*}{$\mathrm{R}^{2}$} & CV \\
\cline { 2 - 7 } & 0 & 5 & 10 & 15 & 20 & 25 & & $(\%)$ \\
\hline Receita bruta (R\$)* & 152,00 & 143,53 & 104,02 & 106,84 & 83,06 & 70,96 & 0,64 & 21,11 \\
Valor agregado bruto (R\$)* & 72,94 & 57,53 & 18,35 & 24,21 & $-11,10$ & $-24,90$ & 0,68 & 10,86 \\
Índice de lucratividade (\%)* & 47,60 & 39,80 & 14,31 & 22,64 & $-42,02$ & $-53,44$ & 0,46 & 9,02 \\
Ponto de equilíbrio* & 197,66 & 215,01 & 214,18 & 206,59 & 235,39 & 239,66 & 0,58 & 4,39 \\
\hline
\end{tabular}

$\mathrm{CV}=$ coeficiente de variação, *Efeito quadrático $(\mathrm{P}<0,05), \mathrm{R}^{2}=$ coeficiente de determinação.

Cruz et al. (2006), Santos \& Grangeiro (2012) e Rufino et al. (2015) afirmam através de seus estudos que, com o efeito positivo obtido a partir da inclusão de alimentos alternativos, $\mathrm{o}$ pequeno produtor que não disponibiliza de recursos financeiros para aquisição de milho e do concentrado, irá se beneficiar e poderá manter sua produção estável. Todavia, se estes alimentos alternativos não conseguirem equiparar seus resultados de desempenho produtivo e econômico aos convencionais, devem ser momentaneamente desconsiderados a integrar a composição das rações, ou novamente estudados a fim de verificar seu potencial de utilização em outras condições.

Seguindo este contexto, também foram observadas diferenças significativas $(\mathrm{P}<0,05)$ no índice de lucratividade $(\mathrm{Y}=$ $\left.0,3121 \mathrm{x}^{2}+0,6420 \mathrm{x}+49,91\right)$, onde através da derivação da equação de regressão foi possível obter o ponto de máxima lucratividade $(53,21 \%)$ no nível de inclusão de $10,28 \%$ de farinha de cará nas rações.

Sohail et al. (2003), Costa et al. (2009) e Rufino et al. (2015) afirmam em seus estudos que antes da tomada de decisões quanto a utilização de um alimento alternativo em escala industrial de produção, deve-se levar em consideração os resultados da analise de rentabilidade e lucratividade deste nas rações, e se possível, constatar a uma relação positiva entre a analise nutricional e a analise produtiva, obtendo reduções significativas de custo e ganhos potenciais.

Quanto ao ponto de equilíbrio, foram observadas diferenças significativas $(\mathrm{P}<0,05)$ onde através da derivação da equação de regressão $\left(\mathrm{Y}=0,09484 \mathrm{x}^{2}\right.$ $0,8903 x+200,58)$, foi possível obter o máximo ponto de equilíbrio $(198,49)$ no 
nível de inclusão de $4,69 \%$ de farinha de cará nas rações.

Segundo Murakami et al. (2009), o ponto de equilíbrio, teoricamente, indica o ponto que define o volume exato de produção que apresente retorno zero. Neste contexto, a partir do aumento dos níveis de farinha de cará nas rações, verificou-se uma tendência de aumento da necessidade do custo necessário a fim de aproximar o ponto de equilíbrio do retorno liquido nulo. Então, percebe-se que quanto maior o nível de adição de farinha de cará nas rações, maior o volume de produção, e consequentemente o custo, exigido para se pagar com os custos totais de produção principalmente os alimentares (VALDIVIÉ et al., 2008; COSTA et al., 2009; MURAKAMI et al., 2009).

Alimentos alternativos em rações para tendem a alterar o desempenho produtivo destas no sentido de redução do custo total de produção, principalmente os alimentos que possuem potencial real de substituição de milho ou farelo de soja, insumos que representam a maior fração das rações, como afirmam Carrijo et al. (2010) e Souza et al. (2011).

Conclui-se, portanto, que a farinha de cará pode ser utilizada como alimento alternativo em rações de poedeiras comerciais leves, tendo o nível de $5 \%$ de inclusão apresentado melhores resultados de desempenho econômico. A partir de $15 \%$ de inclusão, observam-se perdas econômicas significativas.

\section{REFERÊNCIAS}

BASTOS, S.C.; FUENTES, M.F.F.; FREITAS, E.R.; ESPÍNDOLA, G.B.; BRAGA, C.V.B. Efeito da inclusão do farelo de coco em rações para frangos de corte. Revista Agronômica, v.38, p.297-303, 2007.
CARRIJO, A.S.; FASCINA, V.B.; SOUZA, K.M.R. de; RIBEIRO, S. da S.; ALLAMAN, I.B; GARCIA, A. M.L.; HIGA, J.A. Níveis de farelo da raiz integral de mandioca em dietas para fềmeas de frangos caipiras. Revista Brasileira de Saúde e Produção Animal [online], v.11, n.1, p.131-139, 2010.

COSTA, F.G.P., GOULART, C.C.; COSTA, J.S.; SOUZA, C.J.; DOURADO, L.R.B; SILVA, J.H.V. Desempenho, qualidade de ovos e análise econômica da produção de poedeiras semipesadas alimentadas com diferentes níveis de raspa de mandioca. Acta Scientiarum. Animal Sciences, v.31, n.1, p.13-18, 2009.

CRUZ, F.G.G.; PEREIRA FILHO, M.; CHAVES, F. A.L. Efeito da substituição do milho pela farinha de apara de mandioca em rações poedeiras comerciais. Revista Brasileira de Zootecnia, v.35, n.6, p.2303-2308, 2006.

\section{CRUZ, F.G.G. Avicultura caipira na}

Amazônia. Manaus: EDUA, 2011. 80p.

CRUZ, F.G.G.; RUFINO, J.P.F.; MELO, R.D.; FEIJÓ, J.C.; DAMASCENO, J.L.; COSTA, A.P.G.C. Perfil socioeconômico da avicultura no setor primário do Estado do Amazonas, Brasil. Revista em

Agronegócio e Meio Ambiente, v.9, n.2, p.371-391, 2016.

FEIJÓ, J.C.; CRUZ, F.G.G.; MELO, R.D.; RUFINO, J.P.F.; DAMASCENO, J.L.; COSTA, A.P.G.C.; NEGREIROS, T.J.N. Farinha de cará (Dioscorea trifida L.) sobre o desempenho, qualidade do ovo e bioquímica sérica de poedeiras comerciais leves. Revista Brasileira de Saúde e Produção Animal [online], v.17, n.3, p.413-423, 2016. 
FRANZOI, E.E.; SIEWERDT, F.; RUTZ, F. ; BRUM, P.A.R de; GOMES, P.C. Desempenho de frangos de corte alimentados com diferentes níveis de farelo de canola. Ciência Rural, v.28, n.4, p.683-689, 1998.

FREITAS, C.R.G. de; LUDKE, M.C.M.M.; LUDKE, J.V.; RABELLO, C.B.V.; NASCIMENTO, G.R. do; BARBOSA, E.N.R. Inclusão da farinha de varredura de mandioca em rações de frangos de corte. Acta Scientiarum Animal Sciences, v.30, n.2, p.155-163, 2008.

LIMA, R.C.; FUENTES, M.F.F.; FREITAS, E.R.; SUCUPIRA, F.S.; MOREIRA, R.F.; BRAZ, N.M. Farelo de coco na ração de poedeiras comerciais: digestibilidade dos nutrientes, desempenho e qualidade dos ovos. Revista Brasileira de Zootecnia, v.36, n.5, p.1340-1346, 2007.

LOUREIRO, R.R.S.; RABELLO, C.B.V.; LUDKE, J.V.; JUNIOR, W.M.D.; GUIMARÃES, A.A.S.; SILVA, J.H.V. Farelo de tomate (Lycopersicum esculentum Mill.) na alimentação de poedeiras comerciais. Acta Scientarium. Animal Sciences, v.29, n.4, p.387-394, 2007.

MELO, R.D.; CRUZ, F.G.G.; RUFINO, J.P.F.; FEIJO, J.C.; DIAS, E.C.S.; BRANDÃO, A.B.T. Digestibility of Diets Containing Cara Flour (Dioscorea trifida L.) For Laying Hens. International Journal of Poultry Science, v.14, n.3, p.156160, 2015.

MURAKAMI, A.E.; SOUZA, L.M.G.; MASSUDA, E.M.; ALVES, F.V.; GUERRA, R.H.; GARCIA, A.F.Q. Avaliação econômica e desempenho de frangos de corte alimentados com diferentes níveis de milheto em substituição ao milho. Acta

Scientiarum. Animal Sciences, v.31, n.1, p.31-37, 2009.

PELIZER, L.H.; PONTIERI, M.H.; MORAES, I.O. Utilização de resíduos agroindustriais em processos biotecnológicos como perspectiva de redução de impacto ambiental. Journal of Tecnology Management Innovation, v.2, n.1, p.118-127, 2007.

RAMOS-ESCUDERO, F.; SANTOSBUELGA, C.; PÉREZALONSO, J.J.; YÁNES, J.A.; DUENAS, M. HPLC-ESI/MS identification of anthocyanins in Dioscorea trifida L. yam tuber (purple sachapapa). European Food Research and Technology, v.230, p.745-752, 2010.

ROSTAGNO, H.S.; ALBINO, L.F.T.; DONZELE J.L.; GOMES, P.C.; OLIVEIRA, R.F.; LOPES, D.C.; FERREIRA, A.S.; BARRETO, L.S.T.; EUCLIDES, R.F. Tabelas brasileiras para aves e suínos: composição de alimentos e exigências nutricionais. Viçosa: Universidade Federal de Viçosa, 2011. 252p.

RUFINO, J.P.F.; CRUZ, F.G.G.; MILLER, W.P.M.; MELO, R.D.; FEIJÓ, J.C.; CHAGAS, E.O. Análise econômica da inclusão de farinha do resíduo de tucumã (Astrocaryum vulgare Mart) na alimentação de poedeiras comerciais. Revista Brasileira de Saúde e Produção Animal [online], v.16, n.1, p.1-9, 2015.

SANTOS, J.F.; GRANGEIRO, J.I.T. Desempenho de aves caipiras de corte alimentadas com mandioca e palma forrageira enriquecidas com levedura. Tecnologia \& Ciência Agropecuária, v.6, n.2, p.49-54, 2012. 


\section{SAS. Statistical Analysis System.}

SAS/STAT Software Version 9.2. Cary:

SAS Institute Inc., 2008.

SILVA, E.P.; RABELLO, C.B.V.;

DUTRA JÚNIOR, W.M.; LOUREIRO,

R.R.S.; GUIMARÃES, A.A.S.; LIMA, M.B.; ARRUDA, E.M.F.; BARBOSALIMA, R. Análise econômica da inclusão dos resíduos de goiaba e tomate na ração de poedeiras comerciais. Revista Brasileira de Saúde e Produção Animal [online], v.10, n.4, p.774-785, 2009.

SOHAIL, S.S.; BRYANT, M.M.;

ROLAND, Sr. D.A. Influence of dietary fat on economic returns of commercial Leghorns. Journal Applied Poultry Research, v.12, n.3, p.356-361, 2003.

SOUZA, K.M.R.; CARRIJO, A.S.A.; KIEFER, C.B.; FASCINA, V.B.C.; FALCO, A.L.D.; MANVAILER, G.V.E.; GARCÍA, A.M.L. Farelo da raiz integral de mandioca em dietas de frangos de corte tipo caipira. Archivos de Zootecnia, v.60, n.231, p.489-499, 2011.

TOGASHI, C.K.; FONSECA, J.B.; SOARES, R.T.R.N.; COSTA, A.P.D.; SILVEIRA, K.F.; DETMANN, E. Subprodutos do maracujá em dietas para frangos de corte. Acta

Scientiarum. Animal Sciences, v.30, n.4, p.395-400, 2008.

VALDIVIÉ, M.; LEYVA, C.; COBO, R.; ORTIZ, A.; DIEPPA, O.; FEBLES, M. Total substitution of corn by cassava (Manihot esculenta) meal in broiler chicken diets. Cuban Journal of Agricultural Science, v.42, n.1, p.61, 2008.

Data de recebimento: 02/09/2016

Data de aprovação: 04/04/2017 